\title{
PEDIDO DE FORMAÇÃO DO DTLLC
}

http://dx.doi.org/10.11606/issn.2237-1184.v0i33p384-388

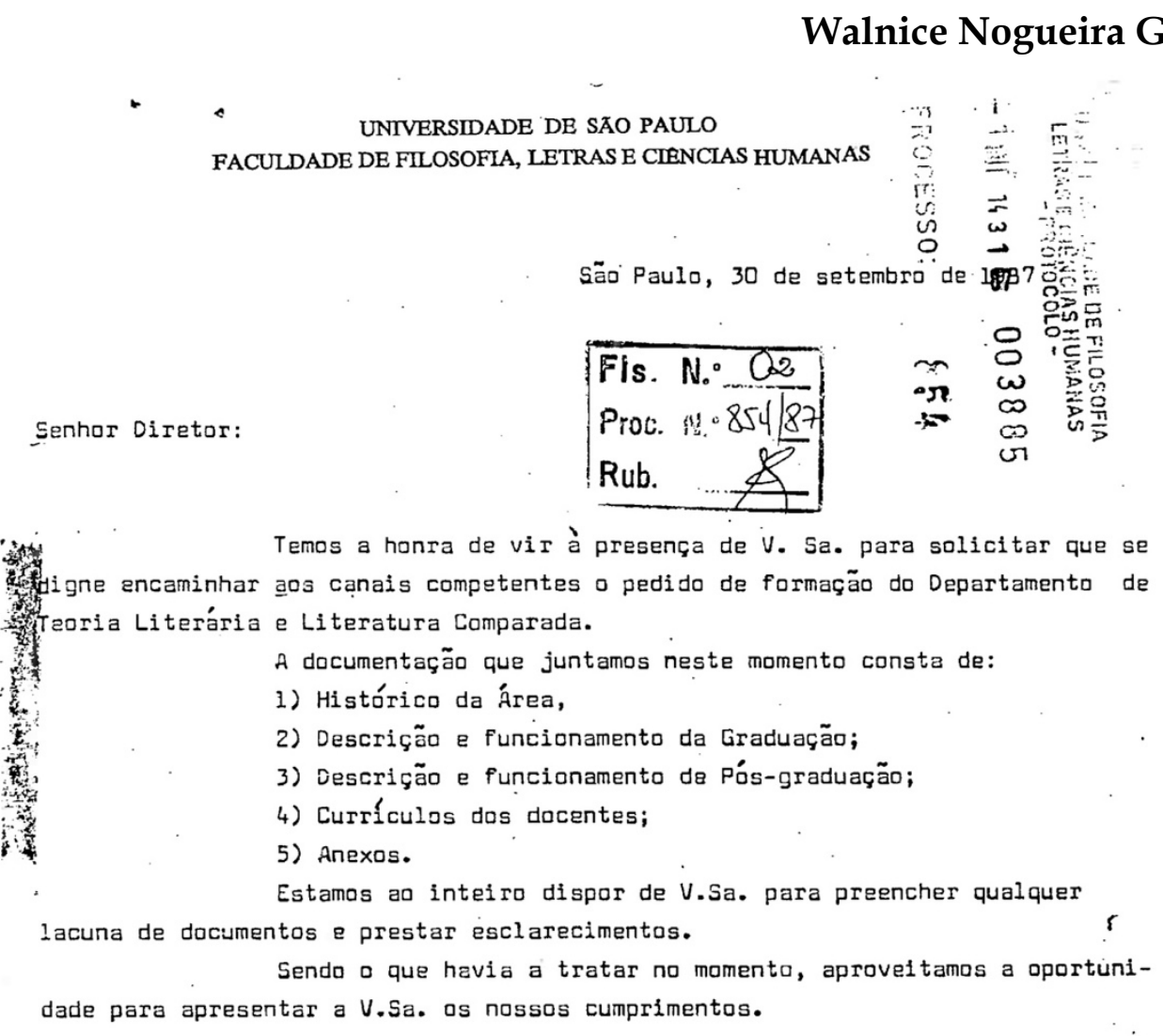

政

Naluicelogienabaloar

Walnice Nogueira Galvão

Responsável pela Área de Teoria Literária

e Literatura Comparada.

Prof. Dr. João Baptista Borges Pereira

DD. Diretor da Faculdade de Filosofia, Letras e Ciências Humanas da USP.

Mod. $02.03 .083-1000 \times 50-2 / 82$

Mod. $02.03 .083-1000 \times 50-2 / 82$ \& imnrimin

I Universidade de São Paulo, São Paulo, São Paulo, Brasil. 
HISTORICO GERAL:

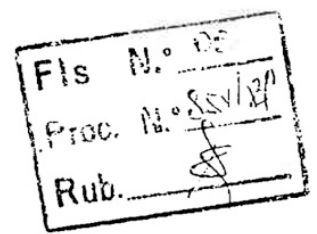

Nossa Area é a primeira, senão uma das primeiras, a serem criadas na Universidade brasileira para o ensino da Teoria Literária.

Pedida à Congregação da então Faculdade de Filoso fia, Ciências e Letras da Universidade de São Paulo já em 1959, com o nome de Teoria Geral da Literatura, incidia sobre estudos gerais introdutórios e estudos teóricos especializados, invocando precedentes como a existência de Introdução ao Estudo do Direi to, Teoria Geral do Estado, Teoria Geral da Educação, Introdução aos Estudos Históricos, Introdução à Filosofia, etc.

No ano de 1961, pela primeira vez nesta Faculdade, Antonio Candido, a cuja iniciativa se deve a criação e o desenvol vimento da área, ministrou o curso de Teoria Geral da Literatura, no âmbito dos cursos de Letras. E ele também o regente do cur so e seu único docente.

No ano seguinte, 1962, e por proposta de Antonio Candido, o curso passa a se chamar Teoria Literária e Literatura Comparada. No mesmo ano o curso é elevado a disciplina, por haver resistência à criação de novas cadeiras, a essa altura mais de sessenta.

Nessa fase inicial, a disciplina é optativa-de vido ao objetivo de testá-la -, constando de um 10 ano geral e iniciatório (denominado Introdução aos Estudos Literários), bem como de um 49 ano (denominado Teoria Literária), este último mu dando de conteúdo a cada um ou dois anos. Ambos ocupavam uma au la por semana: Além deles, havia mais um 59 ano ou Especialização.

Como exemplos desses primeiros cursos, assinalam-se, para o 49 ano, o de Teoria e Análise do Romance (1961 e 1962) e o de O Estudo Analítico do Poema (1963). Quanto aos prí meiros de 50 ano ou Especialização, baseavam-se em seminários e aulas especializadas num problema, visando à aquisição de técnị 
cas avançadas de trabalho. Assim, são mihistrados nes̀se nivel os seguintes cursos: curso de Ecdótica (Edição Crítica), com investigação e análise de manuscritos, bem como critica textual, ten do como objeto de aplicação contos de Machado de Assis, em 1961; seminários sobre Quincas Borba, a cargo do professor mas também dos alunos, visando à construção de uma interpretação coletiva, em 1962; seminários de análise de cinco poemas, escolhidos na obra de Manuel Bandeira, Mário de Andrade, Murilo Mendes, Carios Drummond de Andrade, João Cabral de Mello Neto, em 1963.

o curso tem uma acolhida que excede às expectativas, pois, apesar de optativo e concebido como auxiliar dos de mais, recebe como alunos de 10 ano mais da metade do total dos inscritos em Letras. Então como hoje, tem marcado a linha de cen trar-se em teoria e análise de texto.

Em 1963, uma revisão curricular torna o curso parcialmente obrigatório para o 10 ano de Neolatinas, 30 de Anglogermânicas e 40 de Clássicas e Neolatinas.

Nesse mesmo ano, é aprovada a criação de um Departamento de Teoria Literária e Artes (dentro da Divisão de Letras Modernas), com as seguintes matérias: Teoria e História da Músicà, História e Estética do Cinema, Literatura Dramática, Es tética Geral, História da Arte e Teoria Literária. Este Departạ mento nunca viria a concretizar-se, esvaziado, como foi, pela criação da Escola de Comunicações e Artes (ECA) da USP, que ficou com essas matérias desde então.

No ano de1968, aumenta o número de aulas, que passam a 3 por semana. A essa altura, já havia começado a ampliar-se o corpo docente, premido pelo aumento do corpo discente e do número de aulas.

O esquema básico inicial foi mantido apesar des ses aumentos, constituindo sempre um 10 ano de Introdução aos Es tudos Literários e um 49 ano de Teoria Literāria, os quais se tornaram semestrais em 1969. Quanto ao 59 ano ou Especialização, foi cancelado pela criação da Pós-graduação em 1971, assim se mantendo até hoje. 
Rub.

Também no ano de 1969, pela reforma que transformou a Faculdade de Filosofia, Ciências e Letras em Faculdade de Filosofia, Letras e Ciências Humanas, a Ârea de Teoria Literá ria e Literatura Comparada sofreu um deslocamento equívoco, cujas indesejáveis consequências até hoje se fazem sentir. Com a criação de dois Departamentos de Letras, um de clássicas e Verná culas e outro de Modernas, o que tinha coesão e pertinência, ficaram sobrando duas disciplinas gerais, a de Teoria Literária e Literatura Comparada e a recém-criada de Linguística. Essa mesma reforma expeliu do Departamento de História os igualmente recémcriados Estudos Orientais. Da junção esdrúxula e meramente por conveniência dessas disciplinas sem qualquer afinidade, mas que necessitavam juridicamente da massa crítica que só a Teoria Literária e Literatura Comparada podia fornecer para a constituição de um Departamento, surgiu essa anomalia que sempre foi o Departa mento de Linguistica e Línguas orientais, em cujo titulo jamais sequer figurou o nome de nossa disciplina, sem a qual ele não teria tido existência. Assim gerou-se um terceiro Departamento de Letras, constituído pelas Åreas de Armênio, Årabe, Sânscrito, Rus so, Hebraico, Chinês, Japonês, Tupi e Toponimia (depois Línguas Indigenas), Filologia Românica, Linguística e... Teoria Literária e Literatura Comparada.

Desde então e até hoje, nossa Area, à exceção da de Linguística, agora já constituída em Departamento próprio, é a única a ter massa critica para a sustentação da Pós-graduação do Departamento onde veio a ser encaixada, por necessidade alheia.

Assim sendo, e por força de razões não só cien tíficas mas também históricas, esta situação insustentável, mas que a Area sustentou durante 18 (dezoito) longos e sacrificados anos - pois impediram seu crescimento e a multiplicação desejada das disciplinas que temos condições de oferecer - deve cessar.

Aliás, os Cursos de Orientais vêm conseguindo, finalmente, formar seus próprios mestres e doutores, tendendo a conquistar a autonomia desejável. Esse processo, apesar de extremamente lento, começa a permitir a abertura de uma Pós-Graduação 


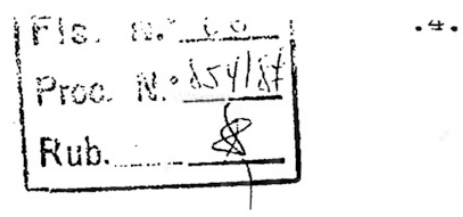

específica, como acontece hoje com Hebraico, cujo credenciamento já foi aprovado pela Comissão de Pós-Graduação desta Faculdade.

Ampliacão e titulação do corpo docente no período

Antonio Candido, já Doutor e Livre-docente quando

fundou a Area, tornou-se Prof. Titular em 1974 e aposentou-se em 1978. O corpo docente que constituiu compôs-se dos seguintes mem bros: Roberto Schwarz (ingressou em 1964 e afastou-se em 1968); Wal nece Nogueira Galvão (ingressou em 1965; Dr.-1970; IU⿺辶-1972;Tit.1985): João Alexandre Barbosa (ingressou em 1967; Dr.-1970;L.D.1973; Adj.-1978; Tit.-1980); Davi Arrigucci Jr. (ingressou em 1967; Dr.-1974); Lígia Chiappini Moraes Leite (ingressou em 1973;Mestre1970; Dr.-1974; L.D.-1986); Teresa de Jesus Pires Vara (ingressou em 1969; Dr.-1973); João Luiz Machado Lafetá (ingressou em 1978; ; Mestre-1973; Dr.- 1980); Iumna Maria Simon (ingressou em 1981; Dr. - 1974); Sandra Margarida Nitrini (contratada em 1973; Mestre-1973; Dr.-1984); Regina Pontieri (ingressou como substituta, por concur so, em 1987; mestre em 1986).

Todos os docentes trabalham em RDIDP, com exce ção de Iumna Maria Simon, com tempo parcial, no momento em fastamen to sem vencimentos, e Regina Pontieri, que ingressou em 1987 pra pre encher esse afastamento por 24 meses, igualmente em tempo parcial. Lucila Ribeiro Bernardet, com turno completo, encontra-se afastada por motivos de saúde desde 1979.

Walnice Nogueira Galvão formou-se em Ciências Sociais em 1961, doutorou-se em Letras em 1970 e tornou-se livre-docente em 1972 pela Universidade de São Paulo. É professora emérita da Faculdade de Filosofia, Letras e Ciências Humanas da USP e foi professora visitante nas Universidades de Austin, Iowa City, Columbia, Paris VIII, Freie Universität Berlin, Poitiers, Colônia, École Normale Supérieure, Oxford, Berlin 2. Tem 45 livros publicados, sobre Guimarães Rosa, Euclides da Cunha, crítica da literatura e da cultura. Escreve assiduamente em jornais e revistas. Contato: wngalvao@uol.com.br 